\title{
Observation and documentation of a Traditional and Complementary Medicine Model in Mexico
}

\author{
Observación y documentación de un modelo de medicina tradicional y \\ complementaria en México
}

Observação e documentação de um modelo de medicina tradicional e complementar no México

Erika Leyva Mendoza

Congregación Mariana Trinitaria A.C. México cmt@cmt.org.mx https://orcid.org/0000-0001-8784-3796

Martín Alberto Rodríguez Brindis Universidad Anáhuac de Oaxaca, México martin.brindis@anahuac.mx https://orcid.org/0000-0001-6268-1604

\begin{abstract}
The use of traditional medicine in Mexico is a fact. The lack of access to health systems, sociocultural aspects and lack of trust in allopath medicine of communities with ancestral knowledge on the topics, makes very relevant the study of these non-allopath medicines. This work is the systematic and scientific observation of an attention model by Congregación Mariana Trinitaria (CMT) in two periods of attention: Oaxaca and Sonora. The aim is to register the intervention in order to determine whether there is a model or protocol of attention, as well as to identify defined therapeutic techniques. The relevance of this study lies in the direct observation by an allopath physician of 60 interventions with an instrument that include both the acceptance of the patients as well as entry and exit interviews with the purpose of considering the impact of the intervention in the feeling of wellbeing of the participant. The sample is made up of patients attending for the first time, which allows to identify if there is an existing acting protocol and thus a model per se. The results
\end{abstract}


demonstrate the identification of four stages with well defined techniques and a feeling of wellbeing in most of the patients.

This study of methodical observation of a CMT Health Mode is a first step of the investigation of a non-allopath medicine that has treated several patients, which is why direct contact is fundamental.

Keywords: Traditional Medicine, Health Model, Therapeutic Techniques, Alternative Medicine Techniques, Complementary Medicine, Integrative Medicine.

\section{Resumen}

El uso de la medicina tradicional en México es un hecho, la falta de acceso a los sistemas de salud, aspectos socioculturales y la falta de confianza en una medicina alopática por comunidades con saberes ancestrales al respecto, hacen muy relevante el estudio de estas medicinas no alopáticas. El presente trabajo es la observación sistemática y científica de un modelo de atención de Congregación Mariana Trinitaria (CMT) en dos jornadas de atención: una en Oaxaca y otra en Sonora. El propósito es registrar la intervención para determinar si existe un modelo o protocolo de atención, así como detectar técnicas terapéuticas definidas. La relevancia de este estudio radica en la observación directa por un médico alópata de 60 intervenciones con un instrumento que incluye tanto la aceptación de los pacientes, así como entrevistas de entrada y salida a fin de tomar en cuenta el impacto de la intervención en el sentimiento de bienestar del participante. La muestra es de pacientes que asistían por primera vez, lo que permite identificar si existe un protocolo de actuación y por ende un modelo como tal. Los resultados arrojan la identificación de cuatro etapas con técnicas muy definidas y con una sensación de bienestar de la mayoría de los atendidos.

Este estudio de observación metódica de un modelo de salud CMT es un primer paso de la investigación de una medicina no alopática que ha tratado a múltiples pacientes, por lo que el contacto directo con el tipo de atención es fundamental.

Palabras clave: Medicina tradicional, modelo de salud, técnicas terapéuticas, técnicas de medicina alternativa, medicina complementaria, medicina integrativa. 


\section{Resumo}

O uso da medicina tradicional no México é um fato, a falta de acesso aos sistemas de saúde, os aspectos socioculturais e a falta de confiança na medicina alopática por parte de comunidades com conhecimentos ancestrais a esse respeito, tornam o estudo desses medicamentos muito relevante. alopático. O presente trabalho é a observação sistemática e científica de um modelo de atendimento da Congregación Mariana Trinitaria (CMT) em dois dias de atendimento: um em Oaxaca e outro em Sonora. O objetivo é registrar a intervenção para determinar se existe um modelo ou protocolo de atendimento, bem como detectar técnicas terapêuticas definidas. A relevância deste estudo reside na observação direta por um médico alopata de 60 intervenções com um instrumento que inclui tanto a aceitação do paciente, quanto as entrevistas de entrada e saída, a fim de levar em consideração o impacto da intervenção no sentimento bem-estar do participante. A amostra é de pacientes que estiveram atendidos pela primeira vez, o que nos permite identificar se existe um protocolo de ação e, portanto, um modelo como tal. Os resultados mostram a identificação de quatro etapas com técnicas bem definidas e com sensação de bem-estar da maioria dos atendidos.

Este estudo de observação metódica de um modelo de saúde CMT é um primeiro passo na investigação de um medicamento não alopático que tem tratado múltiplos pacientes, portanto o contato direto com o tipo de cuidado é essencial.

Palavras-chave: Medicina tradicional, modelo de saúde, técnicas terapêuticas, técnicas de medicina alternativa, medicina complementar, medicina integrativa.

Fecha Recepción: Junio 2020

Fecha Aceptación: Diciembre 2021

\section{Introduction}

New technologies have facilitated research, diagnostics and treatments in the medical area and have contributed to benefit society, particularly as providers of primary health care at the community level, however the heritage that traditional medicine has bequeathed us must not be forgotten, not only for the cultural heritage it represents, but because this significant advance in the health sciences has also made the sector more expensive and, in some way, has made the advance to important sectors of society inaccessible. The doctor-patient encounter has also been altered, turning the former into a health technician who focuses more on the disease than on the patient, and the latter on receiving instructions, rather than a person who requires solidarity in the middle of a disease. The role of traditional medicine is justified 
beyond the cultural and anthropological elements that support it. It is in many ways the only remedy for diseases in large sectors of the population.

For the World Health Organization, traditional medicine is the sum of knowledge, skills and practices based on theories, beliefs and experiences from different cultures, whether or not explainable, and used in health maintenance, as well as in the prevention, diagnosis or treatment of physical or mental illnesses. "Throughout the world, traditional medicine is the main pillar of the provision of health services, or its complement" (WHO 2013).

In this work, the studied model shares ancient techniques with these traditional medicines, but it does not depend on a specific traditional culture, which is why reference is made to traditional, alternative or complementary medicine.

\section{Theoretical framework}

The issue of health and disease has always existed, and for this it is important to approach the Mesoamerican worldview to understand the causes of ills and their ways of healing. López Austin (2016) has shown that within the pre-Hispanic vision, there are complementary opposites (cold-heat, day-night, feminine-masculine) in which the health-disease dichotomy is found. At that time, achieving the midpoint to maintain health and avoid evils, involved finding a balance in relation to the body, society and the gods. The breakdown of this balance was the cause of multiple diseases and the remedies included magic and herbs, as well as the participation of gods and healers.

From pre-Hispanic times to the arrival of the Spanish in our lands, where a repopulation and fusion of both cultures is achieved, the issue of health and disease has always been a relevant issue, for this it is important to approach the Mesoamerican worldview in order to understand the causes of the ills as well as their ways of healing. Important sources to know certain ills are the chronicles of travellers and stories, in which among other things, the illnesses and epidemics are described, in particular, it is important to mention the writings of Fray Bernardino de Sahagún, which refer to different diseases of the indigenous population and the way to counter them.

In the Florentine Codex, the tenth book entitled "Of vices and virtues, these Indian people, and of the members of the whole body, interior and exterior; and of the opposite diseases and medicines; and of the nations that have come to this land" (p. 59). Is without a doubt, an invaluable testimony that gives an idea of the way of conceiving diseases and the remedies 
used by the Mesoamerican natives on the second half of the 16th century. (Sanchez Ruiz 2012).

In section VIII of that same chapter, Fray Bernardino de Sahagún refers to the doctors in the following way: The doctor usually cures and remedies the illnesses; the good doctor is understood, a good connoisseur of the properties of herbs, stones, trees and roots, experienced in cures; it is also a job of knowing how to arrange bones, purge, bleed and cut, to give stiches, and at last, to free from the doors of death. (Sánchez Ruiz 2012).

The bad doctor is mocking, and because he is unskilled, instead of healing, he makes the sick worse with the concoction he gives them, and even sometimes, he uses witchcraft and superstitions to imply that he does good cures.

On the other hand, the acceptance of the knowledge of traditional medicine in the world of health is very varied. The "traditional" term undoubtedly refers to its cultural burden, and this has made the cultural and anthropological aspects the most studied in the face of the health phenomenon, but little has been done for the causal factors of the effects of its therapy. The names of alternative, complementary or integrative medicine refer, unlike the traditional term, to the relationship with allopathic medicine that can be called official. The terminology determines a kind of discrimination of traditional medicine, since the allopathic approach is taken as the primary element of the relationship, thus alternative medicine becomes a substitute for allopathic treatment. Such is the case, for example, of the use of the Saw Palmetto or palmita that is used for benign hypertrophy of the prostate as a substitute for allopathic remedies such as surgery. As Liliana Peredo (2010) refers in her theses "In Canada, Saw Palmetto has been authorized for sale, as a traditional medicine herb to increase urinary flow." (p.4). Traditional medicine becomes complementary when used as part of a main treatment, generally for the management of undesirable side effects of a given treatment, which is the case of parallel treatments used in chemotherapy such as Cannabis Sativa, as the term integrative medicine, is generally belonging to a medicine that does not distinguish between allopathic and traditional medicine, as in the case of the Cuban health system, which uses both medicines interchangeably, including various medical traditions: it is not strange that Cuban treatments include medications, use of herbs and acupuncture, for example. 
Since the approval of Natural and Traditional Medicine (MNT) as a medical specialty within the Cuban Ministry of Public Health (MINSAP) in 1995, the integration of conventional and unconventional practices for the benefit of Medicine was established as a principle, explicitly rejecting the terms of complementary and alternative, because MNT is not an option in addition to or instead of conventional medicine, but rather integrated with, according to the postulates of the World Health Organization (Garcia Salman, 2013).

Traditional medicine is the product of the very own ancestral knowledge of indigenous people. However, knowledge is experiential, which has led to it not being recognized as scientific knowledge, despite its intensive use in the world, and therefore it has become difficult to know where to place traditional medicine and other non-allopathic models within the world of health. However, the more than frequent use of traditional medicine by a highly vulnerable sector, which has little or no access to the health system -also mistrusted by this sector-, the development of an increasingly more technological, highly specialized and of increasing costs, have made the world turn its eyes to these medicines, which is demonstrated under international agreements signed as: Article 24 of Convention 169 of the International Labour Organization on Indigenous and Tribal Independent Peoples signed by Mexico in 1990, the proposal of the Pan American Health Organization (PAHO) on Traditional Medicine and Alternative Therapies in 2002, the resolution of the 56th World Health Assembly, dated May 28, 2003, the Declaration of the United Nations (UN) on the Rights of Indigenous Peoples of September 13, 2007, and resolution EB124.R9 of the 62nd World Health Assembly, of January 26, 2009 (Secretary of Health, 2013).

An even bigger problem is the mismatch of visions: a system that seeks demonstrable, repeatable and objective knowledge against a person who uses medical knowledge to regain one's own, individual and subjective health is at least a disappointment. While non-allopathic medicine is based on the particular case, without worrying about finding the succession of causes and effects that explain the improvement, but rather on the wellbeing that is generated in the person being served. That is why, is important to learn from traditional medicine, whose essence is its holistic vision that seeks to improve those who feel bad, not only from a part of the body, but all of it.

The systematic study of non-allopathic medicines is; therefore important; an alternative that allows the world to rethink its concept of health. However, the road is not easy: a knowledge 


\section{Revista Iberoamericana de las Ciencias de la Salud}

acquired and managed from experience, and which is not asked for explanations, but results, whose basis is tradition itself (World Health Organization, 2020) not reasoned and argued knowledge that allopathic medicine has as a result of the inheritance of the scientific world. Faced with this dilemma, the work aim is to take the first steps into linking both thoughts, establishing whether there is an "action protocol" in integrative medicine and distinguishing whether there are identifiable techniques and possible therapies (sequence of interventions) with the same characteristics. These basic elements are the point of contact between both conceptions of medicine, a descriptive study that does not deepen into the effectiveness and demonstrability of the treatment, but rather defining the treatment itself, as suggested by the WHO in its 2014-2023 Agenda on the traditional medicines and their incorporation into the world of health (World Health Organization, 2020).

Congregación Mariana Trinitaria, through the extensive knowledge inherited from Dr. H.C Catalina Mendoza, who spent 12 years studying traditional medicine, developed a health model and has intervened in the recovery of hundreds of patients by making use of said model. The objective of this study is to observe this model in action, which has been called listening to the body or the CMT Health Model. To determine whether there is a model or protocol of action that is viable to link with allopathic medicine and to take the first steps into a solid investigation of this model of complementary medicine.

About the model, it is important to tell that what is pretended is to become a complementary medicine, so that the people that for tradition do not have confidence in the allopathic medicine, so it can be a support for the health system, The model is based in recognise six dimensions of the human been: physical, intellectual, emotional, spiritual, occupational and social, because of this, the potential to make a allopathic therapy been follow by the patient, when this Therapy y highly aggressive such as the oncological treatment, is better than without it.

For CMT what's mater is welfare or the feeling of it, so the human been can deal with sickness in a beater way, that is the reason that in the first contact, the therapist focus in reduce pain, whatever physical or emotional and the establish the follow up of treatment in three sessions to increase force, detoxify, harmonize or relax the body. 


\section{Method}

This study tries to verify the presence of a model, that is to say: a defined and repeated process, with equally defined techniques for the search of the health of the individual and with a population of 60 continuous interventions (patients) with different ailments through direct observation and recorded in a registration instrument called a case report.

The investigation that was carried out was through direct observation and with observation formats called case reports by an allopathic doctor, who observed 60 interventions, 30 of which were carried out in Ciudad Obregon Sonora and the rest in Oaxaca City.

The observations were registered in an instrument that includes:

- The consent of the patient

- Entry and exit interview with the purpose of measuring the impact of the intervention. The instrument consists of a total of 7 sections:

1. General Data

2. Background and Performed Procedure

3. Made Diagnosis

4. Carried Out Cabinet Study

5. Provided Care

6. Recommendations and Follow-Up Reports

7. Follow-Up and Comments

Additionally, the instrument has four body planes, one at the front, two at the sides and one at the back or reverse.

The instrument allowed to establish if there are clear stages in the medical intervention, and if there are consistent and repeated intervention techniques that suggest defined therapeutic techniques.

It should be noted that the instrument in question has binary type reagents, yes or no, and spaces for observations corresponding to the case, which allows greater objectivity and facilitates the collection of information for processing.

Within the methodology it was important to have had the consent of the participants, for which two letters were developed, the first stating that the patient is aware that he will be treated with integrative medicine and a second of acceptance of participating in the study. This element is essential to give consistency to the ethical part of the investigation.

Regarding the population, a convenience selection that included patients who met the following inclusion criteria was made: people over eighteen years old who agreed to 


\section{Revista Iberoamericana de las Ciencias de la Salud}

participate and signed the consents to receive an integrative medicine treatment and to participate in the study. As exclusion criteria were considered the absence of any of the consents, and as elimination criteria, the wish of not participating in the study expressed during the intervention. The population was made up of 60 participants between nineteen and sixty-six years of age with a percentage of participation of $62 \%$ female and $38 \%$ male.

Regarding the causes of the interventions to said population, the following can be found at table 1 and table 2:

Table 1. Causes of Interventions: Oaxaca City

\begin{tabular}{|l|l|l|}
\hline Malaise & $\%$ & Predominance \\
\hline Articulations Pain & $30 \%$ & Male \\
\hline Throat Pain & $17 \%$ & Mala \\
\hline Headache & $17 \%$ & Female \\
\hline Abdominal Pain & $13 \%$ & Female \\
\hline Sleep Disorders & $10 \%$ & Male \\
\hline Low Back Pain & $6.5 \%$ & Male \\
\hline Cancer & $6.5 \%$ & Both \\
\hline Uterine Myomatosis & $3 \%$ & Female \\
\hline
\end{tabular}

Own elaboration with observation data.

Table 2. Causes of interventions: Ciudad Obregón

\begin{tabular}{|l|l|l|}
\hline Malaise & $\%$ & Predominancia \\
\hline Articulations Pain & $27 \%$ & Male \\
\hline Low Back Pain & $23 \%$ & Female \\
\hline Abdominal Pain & $13 \%$ & Female \\
\hline Headache & $10 \%$ & Female \\
\hline Throat Pain & $7 \%$ & Female \\
\hline Depression & $7 \%$ & Both \\
\hline Diabetes & $3 \%$ & Female \\
\hline Earache & $3 \%$ & Female \\
\hline Sleep Disorders & $3 \%$ & Female \\
\hline Cancer & $3 \%$ & Female \\
\hline
\end{tabular}

Own elaboration with observation data

The study does not attempt to demonstrate the effectiveness of the treatment, but rather is directed to the direct observation of the intervention to find out whether or not there is a defined action protocol that confirms that it is facing a defined system or model of care, as in the world of allopathic medicine. 


\section{Observation}

During the observation, several clear moments within the intervention were distinguished and can be grouped into three major moments: 1. Before the intervention, 2. During the intervention (use of one or more therapeutic techniques) and 3. After the intervention.

Before the intervention, it was observed that several mechanisms are established to create a diagnosis and define the intervention.

The previous techniques to generate the diagnosis can be divided into three:

- Listening to the body (observation of the body)

- Chat (interview with the patient)

- Use of the bell (resonance)

Each of these steps has a central purpose that derives from the application of one or more of the therapeutic techniques.

Listening to the body starts from a careful observation of the face, neck, shoulders, hands, chest, hip, legs and feet. The observation is made in descending order and alterations and imbalances are sought on the vertical axis, dividing the body into two hemispheres, right and left. The imbalances or imbalances of the body suggest to the therapist a first diagnosis and the possible therapeutic intervention, with techniques destined for it called techniques to close and align the body that are described later. In the case of observations, $32 \%$ of the studied population presented these imbalances.

The use of the observation of body maladjustments is well known in traditional medicines, both from the east and the west, as Villate Gómez (2013) suggests:

The MTN is based on a model that uses the clinical method as a fundamental way to reach the diagnosis and is reflected in classic books such as the Neijing from ancient times. The key in the diagnosis is to detect the pattern of the imbalance of the various systems within the human body.

The second part is a chat with the patient, it generally arises from elements observed in the previous stage and they are related to the discomfort that the patient feels, to derive emotional aspects and from these to aspects of the patient's life. The conversation with the patient is crucial to establish the specific ailment, achieve integration with the emotional and life history, it is in this step that the cooperation of the patient is achieved and information is retrieved to define a therapy that addresses emotional aspects and that they are generally established in later stages through a longer therapy called "The Three-Day Therapy" or monthly follow-up, these two aspects are not the reason for the present study, since only the 
direct interventions of one patient were observed. session. The effectiveness of this stage is to achieve full patient trust, and in this study, it was observed that $100 \%$ of the patients stated that they wanted to continue treatment after this stage.

The third moment is the application of the bell. "The bell" is an inspection that is made along the body with a bell in motion caused by a wrist movement. The principle is to look for alterations in the sound of the bell that can even reach silence. For the CMT therapist, the use of the bell is equivalent to the use of a blood pressure cuff or a stethoscope, according to its founder Dr. H. C Catalina Mendoza, in search of more detailed signs of body imbalances. The use of the bell is very similar to the "Hebrew Pendulum" which seeks the mismatch of the pendulum swing as indicative of an energetic irregularity: "everything existing in this world emits different, specific and characteristic radiations from each of the bodies, feelings and emotions. The radiation they emit is like their digital energy impression." (DEUSTO Salud, 2017).

In the investigated population, $100 \%$ of the patients were analysed by this method, which consists of walking the bell with a slight movement of the wrist along the body, from the head down through the central part of the body, and then on the right and left sides, to return to the central part and go down to the lower extremities, the route can be taken several times. It was observed that in $7 \%$ of patients the bell stopped being heard, despite continuing wrist movement. The route of the bell can be accentuated in the place where the alteration or suspension of the sound was established, which specifies the point of intervention, as well as its dimension.

Apparently, it is assumed that the effect of the alteration of the bell clapper, as it happens in the Hebrew Pendulum, is the product of an energy management of the body in the affected area:

... The use of the pendulum is applicable in various areas: decision making, day-to-day organization, choice of therapy, etc. Among alternative therapies, it is frequently used in the balance of the chakras, in the vibrational choice of Bach Flowers, meridian balance of TCM (Traditional Chinese Medicine), nutritional therapies with vitamins and minerals; among others (DEUSTO Salud, 2017).

As can be seen, this moment prior to therapeutic intervention is shared by several traditional medicines, and it is not far from the steps to generate a diagnosis in allopathic medicine, although the latter seeks to rule out possible diagnoses from an exploration that goes from 


\section{Revista Iberoamericana de las Ciencias de la Salud}

the general and to the particular, compared to traditional medicine that seeks the interrelation between physical discomfort, emotional and energetic, meaning it goes from the general to the specific, but to integrate the discomforts, do not rule them out. That is why therapeutic techniques in integrative medicine establish immediate interventions, align and adjust the body, and others at a medium pace (Three-Day Therapy) and other long-term remedies (Monthly Follow-Up).

During the intervention, the identified therapeutic techniques were observed. The following can be highlighted:

- Finger pressure

- Palm pressure

- Fist pressure

- Pressure with the elbow

- Close the body

- Three-day therapy (only mentioned)

- Maintenance follow-up and follow-up (only mentioned)

As you can see, there are 4 pressure techniques, the difference of which lies in the area you are trying to cover. In reality it is the same therapeutic basis, pressing the affected region to restore energy flow, a technique that is already described in the principles of Chinese acupuncture:

The ancient Chinese philosophy, whose existence is reported in books written between 2697 and 2596 B.C., is precisely the theory that underlies acupuncture therapy and many other aspects of oriental medicine; in relation to certain postulates about the relationship of the human being with the universe that surrounds him and the inner workings of these in correspondence with the universal relationships of the energy flow.

With a holistic character, this ancient medical practice considers the human being in its entirety as an ecological element, where a balance must prevail between both: human beings and the total ecological system. Based on this interrelation, one of its essential principles consists precisely in considering its breakdown as the cause of the lack of health or disease (Cabrera Dorta, 2010). 
Pressure techniques consist on pressing the affected body part (usually identified by the use of the bell) repeatedly. At this stage $85 \%$ of patients complain of severe pain in the area that is pressed, $70 \%$ refer to some emotional problem that has them worried and upset, 30\% erupt with sobs or crying loudly expressing emotional conflicts.

The therapist is to listen attentively and respectfully, accompanying the patients and mentioning to expel and let go of those feelings, to vent, during emotional manifestations. The relief continues with pressure and the patients calm down and relax. This is done on 100 $\%$ of the patients.

The pressure on the area can even vary as the treatment progresses, going from pressure with the fist to one with the fingers. What determines the use of a body part depends on two important factors: the surface to be covered and the amount of energy to be redirected (depth of the discomfort). Generally, a discomfort with a long presence and accompanied by emotional elements tends to attacked with the elbow, the affected area is usually not as large, but with a lot of energy retained: the elbow allows that energy to be released through the therapist's arm and fingers (like a fireplace).

Faced with this pressure with the elbow, the pressure with the fingers, the area to be repaired is usually very focused and with a low level of energy to repair, for the larger areas palms or fists are used, the first when there is little energy to re-channel and the second with less energy the therapeutic techniques, size of area, and the energy needed can be seen at table 3 . The use of therapeutic pressure techniques is seen in the following table.

Table 3. Therapeutic techniques: area and energy

\begin{tabular}{|l|l|l|}
\hline Pressure Technique & Size of the Area & Amount of Energy \\
\hline Fingers & Very Focused & Low \\
\hline Elbow & Medium & Very High \\
\hline Palms & Very Large & Medium \\
\hline Fists & Very Large & High \\
\hline
\end{tabular}

Own elaboration with observation data

The concept of redirecting, unblocking or restoring the flow of energy is widely used in various traditional medicines:

Digit-puncture is a therapeutic procedure in traditional Chinese medicine, based on the same principles as acupuncture, since it consists on applying pressure with the fingers on the acupuncture points to maintain or restore the physiological normality of the human body. 
On the other hand, magnetotherapy is the treatment by means of which constant or variable low-frequency magnetic fields act on the body, with multiple general effects, among which stand out, to name a few: analgesic, anti-inflammatory, tissue regenerator and immunological. This therapeutic method has several advantages: great physiological influence, few contraindications, painless, simple execution with high penetrating power and cumulative effect. Its application in acupuncture points for therapeutic purposes is known as magnet-puncture (Vidal Pérez, 2011).

It should be noted that pressure techniques are not massages, but constant pressure at a certain point. In fact, the pressure level is high, thereby seeking to stimulate the point in question, where discomfort may or may not be, for example: sometimes the discomfort is reflected in a part other than the point worked; the jaw is pressed, although the symptom is a headache. On other occasions there is a correspondence between the point where one works and the presence of the discomfort.

The pressure level is really high, even, in the case of pressure with the palm: the therapist places one hand on the other to generate more pressure, so it is not considered a technique of muscle relaxation, but rather of stimulating an energetic point.

Massage, understood as such, is used in the technique of closing the body, where a postural therapy is rather treated.

Posturology thus allows us to correct the mechanical factor of different affections of the locomotor and vertebral system, to better understand the various pathologies and to provide an etiological correction instead of the usual symptomatic treatments whose cost, iatrogenesis and chances of recurrence over time are known. (Bricot, 2008).

The therapeutic technique of closing the body is to align and adjust the body in search of a balance between the two longitudinal hemispheres of the body: aspects such as the shoulders being at the same height, the eyebrows of the face being at the same level, that there is symmetry in belly and hip etc.

To a large extent, many of these corrections occur in conjunction with the above techniques and emerge from the initial observation phase. 
In the model two movements are understood: a tendency to the correction of body maladjustments, and another regarding on terms of energy flow within the body. The first corresponding to a correction, alignment, or adjustment of body posture and the second, from the pressure of points (apparently acupuncture) to seek energetic adjustment.

It is important to note that, in all cases, exist constant communication exchange between the therapist and the patient, progressing little by little on the emotional side in general. All patients tend to open up, some speak, and some others sob and even cry, manifesting emotional situations. In $100 \%$ of the cases observed, the patient was specified the need to carry out the Three-Day Therapy, a treatment that repeats part of the described therapeutic techniques and some additional ones such as sprays, food supplements, salts, among others, and of which there is no direct observation, since this study is limited to the patient's first encounter with the CMT model.

In the result of the observation of the CMT Model, it was found that $100 \%$ of the studied population followed the steps indicated prior to the intervention, that is, observation, exchange of spoken information and application of the bell.

It was also observed that the use of pressure techniques was applied to $100 \%$ of the people who accepted the study, in the same way as the techniques to close the body, regardless of the reason for the visit, that is, apparently there is no relationship between discomfort and therapeutic technique, what changes is the point of application.

Regarding the results of the interventions (which is not the reason for the study) it could be seen that, at the end of the session, during the testimonial that was carried out through an interview, they expressed a reduction of up to $80 \%$ of the initial symptoms manifested and improvement of the discomfort they manifested before starting treatment. $90 \%$ of the patients manifested well-being with the care provided and mentioned "feeling calm, happy and relaxed."

Although these testimonials exist, it is difficult to establish in a direct observation study, the real causes of wellbeing, holistic care of treatment and the use of different therapeutic techniques in the same case makes it difficult to establish this cause-effect relationship.

Regarding the time after the intervention, in all cases the patients were indicated the need for specialized therapy, called the Three-Day Therapy, and which apparently is designed for each patient according to the initial diagnosis. The use of a maintenance therapy called monthly follow-up is also mentioned, in the case of the present study, no observations were made of said treatments, this due to the research design and purpose. 


\section{Revista Iberoamericana de las Ciencias de la Salud}

\section{Discussion}

During the observation it can be tell that there is a very clear protocol to establish the kind of therapeutic treatment, and that the protocol is similar to the allopathic medicine, but with different resources. The use of signs are very similar: allopathic and non-allopathic medicine, starts with a interview to verify sings, but with different point of view, allopathic medicine establish the present and the traditional medicine try to establish the patient history so it can be stablish the origin of the illness. In second terms, there are the study of the symptoms, in the case of CMT Model, it is use the technique of the bell that tray to establish a "measure" of symptoms, just as the allopathic medicine do with clinical and laboratory studies, whoever, both establish a diagnosis based on signs and synthons before they stablish a therapy.

The current research suggests a first step, merely descriptive, but which undoubtedly gives rise to being able to continue the research in a more complete way. Some aspects to be studied are the therapeutic use in the Three-Day Therapy sessions and the Follow Up sessions. Looking for greater consistency between the diagnostic and treatment aspects, not only of the intervention site, but also on the determination of the technique. A study between the relationship of an allopathic diagnosis in contrast to the traditional one, the diagnosis of allopathic medicine depends on the classification and description of very well documented diseases, in the case of traditional medicine terms such as fright, empathy, evil eye, among others, but also introduce terms such as heart attack or embolism, it would be necessary to determine the symptomatology of the terms of non-allopathic medicine and if the common terms are actually the same syndromes.

On the other hand, it would be necessary to investigate whether the same energy centres are used in different traditional medicines for the same symptoms or syndromes, to look for the identification of the research for symptoms in different traditions and their protocol of action, studies similar to this in other medicines. 


\section{Conclusions}

It can be concluded that there is indeed a well-established protocol that starts from the elaboration of a diagnosis through three moments: the observation, the chat and the application of the bell, and from which it is therapeutically intervened through very well delineated techniques of pressure and alignment and adjustment of the body, just as it was attested that the use of a therapeutic technique does not depend on the condition, and that it is applied at certain points according to the diagnostic process, and it is then possible to declare a model defined by clear and unique phases. Also, it could be seen that after the first intervention, there is an individualized therapy phase (Three-Day Therapy) and long-term follow-up (Maintenance Therapy), making up four very clear stages in the model.

There is a coincidence in allopathic medicine in the sense of also having a diagnostic process and then therapeutic intervention, although in the case of allopathic medicine, it is based on the elimination of a syndrome that is determined by clear symptoms, while in the observed model treatment is determined by what the body reflects (listening to the body) by what it tries to be holistic. However, the fact of starting from the same place leads to future scientific research in favour of the development of a non-allopathic medicine that is alive and used by a large percentage of the population.

\section{Future research}

As part of the research work, it is important to point out the relationship of allopathic medicine with traditional medicine, in particular that in the CMT model, which is why a more continuous intervention of an allopathic doctor is intended to follow up on cases with very well-defined purposes.

Investigate additional therapies to those described in the first contact, particularly within the

three-day therapy, the relationship of these techniques with discomfort and initial diagnosis, as well as their effects.

In a second phase, the aim is to validate the diagnoses through the "translation" of the discomforts into known syndromes and to verify their efficiency, both in the parameters of traditional medicine, as well as in those used in allopathic medicine. It is evident that part of the work of this stage requires establishing the possible physiological and biochemical causes or explanations of the therapies described, in order to provide inputs for deeper 


\section{Revista Iberoamericana de las Ciencias de la Salud}

investigations. The scope of this research is typical of clinical research, so its results arise from the opportunity of direct observation of cases.

On the other hand, the continuous presence of a researcher allows monitoring particular conditions, forming control groups and observing the evolution of these cases and determining whether there is consistency in both the treatment and its evolution, or if it was the case, look for variants and their causes. In this particular case, conditions with prolonged therapeutics become important, particularly those with complex allopathic treatments such as chemotherapies, and in which case follow up on the promotion of adherence to treatment and the influence of the health model on this attachment.

\section{References}

Bricot, B. (2008). Postura normal y posturas patológicas. Revista IPP,1(2), 1-13.

Cabrera Dorta, T., Quiñones Cabrera, D., Guevara Pérez, E., Garriga Alfonso, N., Pons Carol, M., \& Estrada Vaillant, A. (noviembre de 2010). Evaluación del cumplimiento de las indicaciones para introducir la Medicina Tradicional y Natural a la Morfofisiología de Medicina, en Matanzas. (U. d. Matanzas, Ed.) Revista médica electrónica, 32(6). Recuperado el 12 de enero de 2020, de :http://www.revmatanzas.sld.cu/revista\%20medica/ano\%202010/vol6\%202010/tem a04.htm

DEUSTO, Salud. (mayo 9 de 2017). DEUSTO SALUD. De la radiestría: el péndulo como método de diagnóstico. Recuperado el 10 de octubre de 2019, de https://www.deustosalud.com/blog/terapias-naturales/radiestesia-pendulo-metododiagnostico

García Salman, J. D. (2013). Consideraciones sobre la Medicina Natural y Tradicional, el método científico y el sistema de salud cubano. Revista Cubana de Salud Pública, 39(3), 540-555.

López Austin, A. (2016). Sobre la cosmovisión. Arqueología mexicana, (68), 8-24.

Organizacion Mundial de la Salud. (2013). Estrategia de la OMS sobre medicina tradicional 2014-2023. Recuperado el 14 de enero de 2020, de : http://apps.who.int/medicinedocs/documents/s21201es/s21201es.pdf

Organización Mundial de la Salud. (13 de Enero de 2020). World Health Organization. Obtenido de Implementation of the WHO Traditional Medicine Strategy 2014-2023 
de: https://www.who.int/health-topics/traditional-complementary-and-integrativemedicine\#tab=tab_1

Peredo Silva, L. (2010). Protocolo para evaluar el perfil de seguridad de un extracto de CO2 fluido supercrítico de Saw Palmetto (Serenoa repens W. Bartram).

Sanchez Ruiz, J. F. (2012). La farmacia, la medicina y la herbolaria del codice florentino. Revista Mexicana de Ciencias Farmacéuticas, 55-66.

Secretaria de Salud. (2013). Guía de implantación. Fortalecimiento de los servicios de salud con medicina tradicional. (S. d. salud, Ed.) México, Ciudad de México, México. Obtenido de Fortalecimiento de los servicios de salud con medicina tradicional de: https://www.gob.mx/cms/uploads/attachment/file/38485/ModeloFortalecimientoMe dicinaTradicional.pdf

Vidal Pérez, T. E. (octubre de 2011). Efectividad de la digitopuntura y electromagnetopuntura en pacientes con ptosis palpebral congénita. MEDISAN. Recuperado el 23 de noviembre de 2019, de: http://scielo.sld.cu/scielo.php?pid=S102930192011001000007\&script=sci_arttext\&tlng=en

Villate Gómez, F. (2013). Consideraciones de la medicina tradicional en su combinación con la medicina occidental y el enfoque diagnóstico. Revista Cubana de Medicina Militar, 42(1), 124-131. 


\begin{tabular}{|l|l|}
\hline Rol de Contribución & Autor (es) \\
\hline Conceptualización & Martín Alberto Rodríguez Brindis \\
\hline Metodología & Erika Leyva Mendoza \\
\hline Software & N/A \\
\hline Validación & $\begin{array}{l}\text { Martín Alberto Rodríguez Brindis (Igual) } \\
\text { Erika Leyva Mendoza (Igual) }\end{array}$ \\
\hline Análisis Formal & Martín Alberto Rodríguez Brindis \\
\hline Investigación & Martín Alberto Rodríguez Brindis \\
\hline Recursos & Erika Leyva Mendoza. \\
\hline Curación de datos & Martín Alberto Rodríguez Brindis \\
\hline $\begin{array}{l}\text { Escritura - Preparación del } \\
\text { borrador original }\end{array}$ & $\begin{array}{l}\text { Martín Alberto Rodríguez Brindis (principal) } \\
\text { Erika Leyva Mendoza (apoyo) }\end{array}$ \\
\hline $\begin{array}{l}\text { Escritura - Revisión y } \\
\text { edición }\end{array}$ & Martín Alberto Rodríguez Brindis \\
\hline Visualización & $\begin{array}{l}\text { Martín Alberto Rodríguez Brindis (Principal) } \\
\text { Erika Leyva Mendoza (apoyo) }\end{array}$ \\
\hline Supervisión & Martín Alberto Rodríguez Brindis \\
\hline Administración de Proyectos & Martín Alberto Rodríguez Brindis \\
\hline Adquisición de fondos & Erika Leyva Mendoza \\
\hline
\end{tabular}

